\title{
Autosomal recessive mendelian susceptibility to mycobacterial diseases due to partial IFNgammaR2 deficiency
}

INSERM

\section{Source}

INSERM. (1999). Orphanet: an online rare disease and orphan drug data base. Autosomal recessive mendelian susceptibility to mycobacterial diseases due to partial IFNgammaR2 deficiency. ORPHA:319574

Autosomal recessive mendelian susceptibility to mycobacterial diseases (MSMD) due to partial IFNgammaR2 deficiency is a genetic variant of MSMD (see this term) characterized by a partial deficiency in IFN-gammaR2, leading to a residual response to IFN-gamma and consequently to recurrent, moderately severe infections with bacillus Calmette-Guérin (BCG) and other environmental mycobacteria (EM). 